\title{
Defensoria pública brasileira: sua história
}

\author{
Simone dos Santos Oliveira ${ }^{1}$
}

\section{Resumo}

O artigo trata da relação entre o Direito e a Sociedade; o importante papel do judiciário para realização da justiça social; da garantia do acesso à justiça através da Defensoria Pública e sua história no ordenamento jurídico brasileiro. 0 principal objetivo do trabalho é despertar o interesse para esta importante função estatal que é tão desprivilegiada e os reflexos da falta de estruturação da instituição na vida da população, principalmente dos indivíduos mais pobres.

Palavras-Chave: Direito; Sociedade; Acesso à justiça; História; Defensoria pública.

\section{Introdução}

A idéia deste trabalho nasceu da nossa indignação gerada pela observação da realidade social, na qual constatamos que apesar de existir de uma Constituição Federal conhecida como Constituição Cidadã, composta por muitas normas protetivas, os benefícios que deveriam advir de tal legislação não se realizam e não alcançam os progressos sociais esperados, visto que a realidade aponta que a população está cada vez mais distante e alheia às estruturas estatais criadas para lhe dar suporte e garantir uma vida digna. A função jurisdicional do Estado deveria desempenhar um papel importante, juntamente com as funções executiva e legislativa, uma vez que é ela que tem maior débito perante a sociedade, porque não raras vezes se fecha em si mesma, não se volta para a sociedade para compreendê-la e, apesar disso, acaba decidindo a vida de pessoas das quais ignora a realidade.

Nesse sentido, João Baptista Herkenhoff (1997, p. 129): “A par da reforma de códigos e leis, é indispensável reformar a estrutura judiciária: seu pessoal, sua dinâmica, suas bases materiais, suas praxes obsoletas".

A partir de tal cenário, fica latente a urgência de repensar a ideologia dos membros do judiciário e também da valorização de alternativas, tais como: os Juizados Especiais, o

1 Pós-graduanda em Direito do Estado/Constitucional/2006 - Universidade Estadual de Londrina. 
trabalho do Ministério Público protegendo a sociedade e a Defensoria Pública atuante em todas as localidades do país.

Frente ao acima exposto, a atuação da Defensoria Pública, enquanto instrumento de acesso à justiça, é indispensável na busca da tão sonhada justiça social. Isto posto, ela passará a ser o foco principal desta reflexão.

\section{Jurisdicionalização da sociedade}

Antes de adentrarmos ao tema central - a Defensoria Pública e sua história - faz-se necessário situar o leitor sobre os motivos da jurisdicionalização da sociedade, sua importância, seus reflexos sociais e também os problemas relacionados ao Direito e à sociedade.

A constatação de que o ser humano é um ser social vem de longa data, pois o homem necessita de seus semelhantes para alcançar a realização plena, e na mesma medida que o homem precisa viver em grupo a sociedade necessita de regras para pacificá-la e tornar essa convivência harmoniosa. Daí ser a expressão ubi societas ibu jus emblemática do entendimento de que não existe sociedade sem direitos.

Antônio Carlos de Araújo Cintra (2003, p. 19) explica que a correlação entre direito e sociedade existe porque o direito exerce função ordenadora, isto é, a coordenação dos interesses manifestados na vida social, de modo a organizar a cooperação entre pessoas e compor os conflitos que emergem entre seus membros, como asseveram Sérgio Cruz Arenhart e Luiz Guilherme Marinoni (2004, p. 27),

\footnotetext{
é necessária a existência de regras jurídicas para a harmônica convivência social, e como pode existir dúvida em torno de sua interpretação, ou mesmo intenção de desrespeitá-las, podem eclodir no seio da sociedade conflitos de interesses.

Como a insatisfação de um interesse, principalmente quando essa insatisfação decorre da resistência de alguém, pode gerar tensão aos contedores e até mesma tensão social, é importante que os conflitos sejam eliminados e encontrada a paz social, escopo do Estado.
}

As regras impostas pela vida em grupo são de vários tipos: morais, éticas, jurídicas, entre outras, sendo que as jurídicas são as que possuem maior poder de coação sobre os indivíduos. Além do que, apenas elas têm relação direta com o objeto deste estudo, daí porque discorreremos sobre tais normas, que segundo Humberto Theodoro Jr. (2004, p. 5) é 
impossível a vida em sociedade sem uma normatização do comportamento humano. Daí surgir o Direito como conjunto de normas gerais e positivas, disciplinadoras da vida social.

Mas não basta traçar a norma de conduta. O equilíbrio e o desenvolvimento sociais só ocorrem se a observância das regras jurídicas fizer-se obrigatória.

Assim, o Estado não apenas cuida de elaborar as leis, mas, especificamente, instituir meios de imposição coativa do comando expresso na norma.

Antônio Carlos Wolkmer (2003, p. 19) confirma que a vida em sociedade necessita de normas, porque

toda a cultura tem um aspecto normativo, cabendo-lhe delimitar a existencialidade de regras e valores que institucionalizam modelos de conduta. Cada sociedade esforça-se para assegurar uma determinada ordem social, instrumentalizando normas de regulamentação essenciais, capazes de atuar como sistema eficaz de controle social, elemento material para prevenir, remediar ou castigar os desvios das regras prescritas. A lei expressa a presença de um direito ordenado na tradição e nas práticas costumeiras que mantêm a coesão do grupo social (WOLKMER, 2003, p. 19).

Apesar da existência de regras e padrões pré-estabelecidos socialmente, é impossível evitar conflitos entre os cidadãos e entre o Estado e os cidadãos. Isto acontece porque o ser humano é de natureza complexa e quando ele trava relações sociais a complexidade afigura-se maior.

Diante disso, o Estado, através da organização e normas, tem o poder de dirimir conflitos que envolvem as pessoas (inclusive o próprio Estado), decidindo sobre as pretensões apresentadas e impondo as decisões.

Entre os povos primitivos a tutela dos interesses era feita pelas próprias partes. Naquela época, prevalecia a justiça privada e não a pública (administrada pelo Estado). A transição entre a justiça privada e a pública adveio da longa evolução dos povos.

José Carlos Moreira Alves (1992, p. 124) apresenta em quatro etapas a provável evolução da proteção dos direitos entre os povos primitivos:

- na primeira etapa, os conflitos entre particulares eram, em regra, resolvidos pela força (entre a vítima e o ofensor, ou entre grupos de que cada um deles faz parte), mas o Estado - então incipiente - intervém em questões vinculadas à religião; e os costumes vão estabelecendo, paulatinamente, regras para distinguir a violência legítima da ilegítima;

- na segunda, surge o arbitramento obrigatório: a vítima, ao invés de usar da vingança individual ou coletiva contra o ofensor, prefere, de acordo com este, 
receber uma indenização que a ambos parece justa, ou escolher um terceiro (o árbitro) para fixá-la;

- na terceira etapa, nasce o arbitramento obrigatório: o facultativo só era realizado quando os litigantes o desejassem, e, como esse acordo nem sempre existia, daí resultava que, as mais das vezes, se continuava a empregar a violência para a defesa do interesse violado; por isso, o Estado não só passou a obrigar os litigantes a escolherem árbitro que determinasse a indenização a ser paga pelo ofensor, mas também a assegurar a execução da sentença, se, porventura, o réu não quisesse cumpri-la, e

- finalmente, na quarta e última etapa, o Estado afasta o emprego da justiça privada, e, por funcionários seus, resolve os conflitos de interesses surgidos entre os indivíduos, executando a força se necessário, a sentença.

Segundo José Reinaldo de Lima Lopes (2003, p.398) o direito do Estado julgar o conflito entre os cidadãos se consolidou com o desenvolvimento da forma moderna de Estado, processo que se iniciou na Baixa Idade Média, com a progressiva centralização monárquica e nacional da Europa Ocidental. Junto com a centralização do poder de decisão sobre os conflitos na mão do Estado ocorreu a profissionalização dos atores processuais, como explica:

Pode-se também perceber que a profissionalização crescente dos atores relevantes (advogados, juízes, promotores, cartorários, policiais) acompanhou o desenvolvimento das formas estatais modernas. $O$ direito do antigo regime, por seu turno, foi obrigado a conviver com os não-profissionais: viveu um conflito permanente entre as duas formas de poder.

De um lado, como impedir, numa sociedade estratificada, estamental e pouco urbanizada (como as sociedades européias e respectivas colônias americanas), que o mandonismo e o senhorio local se apropriassem da justiça? De outro lado, como evitar que a centralização e a profissionalização alienassem o povo, ou cidadão ordinário, das funções públicas da administração da justiça? Ao longo da história, a presença dos leigos ou a participação popular na administração da justiça assumiu diversas formas (LOPES, 2003, p. 399).

Ainda sobre a profissionalização das funções judiciais:

[...] a primeira era o fim da gratuidade da justiça, a segunda o distanciamento do saber jurídico da experiência comum dos leigos. Se a função de julgar ou a organização dos tribunais exigia um grupo especial de pessoas, que não os cidadãos comuns, que não por simples honra de servir o bem comum, era preciso remunerar seus serviços, criando prebendas, rendas ou taxas. $O$ fim da gratuidade da justiça fez que surgisse o problema da defesa do direito dos pobres (privilégio que a Igreja se deu, avocando para a jurisdição eclesiástica, ex ratione personae, as causas das miserabiles personae) e do dever (ou não dever) da advocacia gratuita em favor dos miseráveis. O distanciamento do saber jurídico do senso comum de razoabilidade estabeleceu entre os juristas uma linguagem técnica expressa num jargão, não mais língua falada pela população em geral (LOPES, 2003, p. 416). 
Consideramos que a profissionalização das pessoas envolvidas no processo de julgamento das lides foi fator determinante para o afastamento do cidadão comum dos órgãos jurisdicionais. A partir daí, paulatinamente, o processo se afasta dos leigos exigindo cada vez mais, conhecimentos extremamente técnicos, e o indivíduo passa a ser refém dos detentores do conhecimento. Tais detentores são os profissionais da área jurídica que permaneceram por muito tempo afastados de todas as outras áreas do conhecimento acreditando que o Direito se bastava por si mesmo, esquecendo-se de uma importante lição: que o Direito existe para servir ao homem e não o homem servir o Direito. E foi esse comportamento que contribuiu de forma decisiva para dificultar o acesso à Justiça.

Nos últimos tempos vem ocorrendo uma revolução no pensamento jurídico, e nela prospera uma nova visão que passa a considerar o Direito em função da sociedade, contudo muitos profissionais ainda continuam com a idéia arraigada de que nada pode atingir o Direito Positivo e que o conhecimento jurídico não deve ser acessível a toda população.

Sobre a transformação do pensamento jurídico e do sistema judicial:

\begin{abstract}
a grande tentativa de reforma e ruptura do sistema judicial e processual deu-se com a Revolução Francesa, no que diz respeito ao direito continental. As funções judiciais haviam sido apropriadas por toda parte como cargos patrimoniais, como são até hoje os cartórios privados. O processo revolucionário desejava incluir a justiça na esfera da cidadania formal e liberal, e para tanto impôs novas características. Em primeiro lugar toda justiça precisava ser (re) ligada diretamente ao estado: as jurisdições não estatais foram suprimidas (como a eclesiástica) ou consideradas existentes por permissão e sob supervisão do Estado (como os tribunais mercantis). Em segundo lugar, considerando que a soberania popular se exercia pela eleição dos oficiais públicos, havia dois caminhos a seguir quanto ao aparelho judicial: ou se elegiam os juízes (solução adotada inicialmente para algumas jurisdições) ou se subordinavam os juízes à vontade popular expressa nas leis votadas pelos representantes eleitos (solução que se generaliza) (LOPES, 2003, p. 417).
\end{abstract}

Segundo Humberto Theodoro Jr. (2004, p. 5), cabe ao Estado a função jurisdicional, pois ele utiliza método próprio, que é o processo. Para regular esse método de composição dos litígios, cria, o Estado, normas jurídicas que formam o direito processual, também denominado formal ou instrumental, por servir de forma ou instrumento de atuação da vontade concreta das leis de direito material ou substancial para solucionar o conflito de interesses estabelecidos entre as partes. 


\section{A necessidade de garantir o acesso à justiça}

A história demonstra que as normas jurídicas e o sistema judiciário foram criados com intuito de pacificar, tornar mais justa e melhorar a vida das pessoas, porém por muitos fatores - sendo os principais deles a desigualdade e os elevados níveis de pobreza - os indivíduos não possuem a mesma capacidade de fazer valer os direitos que lhes são formalmente garantidos. Enquanto os que possuem maior poder aquisitivo têm acesso facilitado aos órgãos estatais, os mais pobres, além de viverem em uma situação precária e terem quase todos os seus direitos básicos desrespeitados (saúde, educação, saneamento básico, dentre outros) são também privados de levar seus problemas e contendas aos órgãos administrativos ou judiciários, por lhes faltar conhecimento e recursos que possibilitem o franco acesso ao judiciário ou executivo.

Antônio Carlos de Araújo Cintra (2003, p.25), fala sobre a função jurisdicional na atualidade:

hoje, prevalecendo as idéias do Estado social, em que ao Estado se reconhece a função fundamental de promover a plena realização dos valores humanos, isso deve servir, de um lado, para pôr em destaque a função jurisdicional pacificadora como fator de eliminação dos conflitos que afligem as pessoas e Ihes trazem angústia; de outro, para advertir os encarregados do sistema, quanto á necessidade de fazer do processo um meio efetivo para a realização da justiça.

Considerando o quadro acima é que visualizamos a relevância de meios facilitadores do acesso à Justiça, mais especificamente da Defensoria Pública que deve contribuir para a melhoria das condições daqueles que necessitam de auxílio para que seus direitos sejam respeitados. Defendemos o pressuposto que se o direito foi criado para melhorar e facilitar a vida das pessoas é inadmissível que a legislação e o judiciário se afastem da realidade de seus jurisdicionados. Diante do exposto é possível afirmarmos que há um "abismo" entre os indivíduos que são efetivamente tutelados pelo Estado e recebem todos os benefícios a que têm direito e a grande massa de excluídos. Estes mal conhecem a gama de direitos dos quais são destinatários. 


\section{Primórdios da defensoria pública e defensoria pública no Brasil}

Se a Defensoria Pública se afirma como instrumento de defesa dos direitos é importante conhecer sua história, bem como, seus antecedentes mais remotos.

Encontramos registro do tratamento especial dispensado àqueles que se encontravam em situação desprivilegiada no Código de Hamurabi, que data de 1694 a.C:

Parágrafo 48, XIV Se um awilum ${ }^{2}$ tem sobre si uma dívida e (se) $\mathrm{Adad}^{3}$ inundou seu campo ou a torrente (o) carregou, ou (ainda) por falta de água, não cresceu cevada no campo, nesse ato ele não dará cevada ao seu credor. Ele umedecerá a sua tábua e não pagará os juros desse ano (BOUZON, 2003 p. 86).

Na passagem acima, do Código de Hamurabi, apesar de não abordar propriamente a idéia de defesa do acesso à Justiça, notamos que já existe a preocupação em proteger aquele que se encontra em uma situação de dificuldade. Sendo assim, o homem, naquele momento, já estava atento à necessidade de proteção aos que se encontrassem em situação desigual.

Em Atenas e em Roma encontramos formas de proteção aos necessitados mais parecidas com as que adotamos hoje.

Em Atenas, na Grécia antiga, podemos vislumbrar uma atuação mais concreta junto aos pobres. Nesta região eram designados anualmente dez advogados para defender esses menos favorecidos contra os poderosos diante dos tribunais civis e criminais. Em Roma, existiam diversos dispositivos legais que resguardavam os direitos dos necessitados, e era uma questão de honra para os governantes, observar se seus governados mantinham entre si uma certa igualdade perante a lei, cabendo a estes governantes sanar qualquer abuso (ORIGEM, 2006).

Humberto Peña Moraes (1984, p.21) registra que se atribui a Constantino (288-337) a primeira iniciativa de ordem legal que se incorporou à Legislação de Justiniano (483-565): prover advogado a quem não possuísse meios materiais para remunerar um defensor.

Com o aparecimento do cristianismo, a caridade, um dos grandes temas da doutrina cristã, impôs aos advogados o dever da defesa, sem honorários, e aos juízes o de julgar, renunciando às custas, mas na Idade Média, por influência do feudalismo, os costumes e a idéia do patrocínio profissional aos indigentes foram sendo deixados de lado.

\footnotetext{
Awilum: representava, na sociedade babilônica, o homem livre, o cidadão em pleno uso de seus direitos.
}

3 Adad: forças da natureza. 
Após a revolução Francesa, em 1789, e com a difusão dos ideais de igualdade, liberdade e fraternidade, o Estado foi impulsionado a organizar instituições oficiais para prestação de assistência judiciária aos pobres. Porém, isto não quer dizer que foi implantada assistência aos necessitados de forma satisfatória. Neste momento histórico, havia apenas a preocupação com a igualdade formal e imperava a idéia dos direitos individuais.

O primeiro grande impulso dado à questão acesso à justiça ocorreu na década de 70, através do "Movimento de Acesso à Justiça". Porém, o reconhecimento da necessidade de propiciar aos desprivilegiados do sistema condições de acesso à Justiça e o direito à igualdade vem de longa data, pois as sociedades antigas já se preocupavam com tal problema.

a própria natureza com seus desígnios supranaturais, estabelece, entre os homens, inúmeras diferenças fundamentais, inclusive, de fortuna, impondo a todos a tão discutida, mas não menos verdadeira, desigualdade natural, fundamento de toda teoria moderna da Igualdade perante a Lei (MORAES, 1984, p.18).

Portanto, conforme podemos verificar, já nas antigas sociedades organizadas havia a preocupação de garantir igualdade de tratamento e de oportunidades diante das diferenças individuais causadas pela desigualdade da fortuna.

Apercebidos que tal desigualdade ocasionaria, fatalmente, diferença de oportunidade, procuraram inserir, nos seus ordenamentos legais, princípios de ordem pública que ensejassem aos pobres a mesma oportunidade de invocar jurisdição, possível de ser exercida, por expensas próprias pelos afortunados (MORAES, 1984, p. 19).

O asseguramento do direito de acesso de todos à prestação jurisdicional, independentemente de suficiência de recursos, permaneceu, no mundo moderno, mantidas as peculiaridades locais, como um dos principais objetivos das legislações próprias, aperfeiçoada, sob o influxo de novas concepções sócio-jurídicas, econômicas e políticas, embora ainda sejam registrados sistemas bastante primários de ajuda legal (MORAES, 1984, p. 28).

No Brasil, a Defensoria Pública é a nossa mais nova instituição jurídica. Ela, em média, foi instituída há treze anos, nas diversas Unidades da Federação nas quais atua (BRASIL, 2004). No entanto, podemos citar iniciativas e normas, no decorrer de nossa história, que dizem respeito à busca pela garantia da igualdade e acesso à justiça que atualmente a Defensoria Pública passa a defender. 
Em alguns textos consultados, observamos que os autores fizeram referência às Ordenações Afonsinas ${ }^{4}$ (Livro 3으, Título 8으, Livro 3으 e Titulo 5ㅇ) como sendo a primeira iniciativa de amparo aos menos favorecidos de que se teve conhecimento em nosso país.

Todavia, a maioria dos estudiosos do tema afirma que a primeira manifestação acerca da assistência jurídica, no Brasil, encontra-se nas Ordenações Filipinas, no Livro III, Título 84, parágrafo 10 :

Em sendo o agravante tão pobre que jure não ter bens móveis, nem de raiz, nem por onde pague o agravo, e dizendo na audiência uma vez o Pater Noster pela alma del Rey Don Diniz, ser-lha-á havido como que pagasse os novecentos reis, contanto que tire de tudo certidão dentro do tempo, em que havia de pagar o gravo. (DEFENSORIA, 2006)

Humberto Peña Moraes (1984, p. 94) comenta que os dizeres acima correspondem ao que hoje chamamos de afirmação de pobreza.

Embora esta Ordenação date de 1603, somente em 1823 estes dispositivos vieram a vigorar por força de lei. Alguns anos depois, outros dispositivos vieram sobre forma de leis e regulamentos, estabelecendo, de forma mais concreta, a assistência judiciária no país. Em um primeiro momento, essas leis disciplinavam essa assistência em processos penais. Entretanto, posteriormente, outras leis vieram lhe dar um caráter mais abrangente, compreendendo o processo civil.

Apesar da existência dos dispositivos citados acima, não conseguimos encontrar registros de que no período imperial o Estado investia na assistência jurídica, através de

4 Ordenações: Compilações de leis portuguesas que vigoraram de 1446 a 1867, até ser aprovado o primeiro Código Civil de Portugal. No Brasil, foram mantidas até 1916, quando se deu a promulgação do nosso Código Civil (L. 3.071, de 1.1.1916) que, no Art. 1.807.

As Ordenações Afonsinas são uma coletânea de leis promulgadas, como primeira compilação oficial do século XV, durante o reinado de Dom Afonso V. Várias vezes as Cortes tinham pedido a D. João I a organização de uma coletânea em que se coordenasse e atualizasse o direito vigente, para a boa fé e fácil administração na justiça. Para levar a cabo essa obra, designou D. Duarte o doutor Rui Fernandes, que acabaria o trabalho em 1446 em Arruda.

Este projeto foi revisto por ordem do infante D. Pedro, que lhe introduziu algumas alterações, fazendo parte da comissão Lopo Vasques, corregedor da cidade de Lisboa, e os desembargadores Luís Martins e Fernão Rodrigues. Talvez em 1448, ainda durante a regência de D. Pedro, tenha acabado a revisão embora as Ordenações incluam leis de 1454. Desconhece-se as partes de autoria de João Mendes e Rui Fernandes. A respeito das fontes utilizadas, verifica-se que os compiladores aproveitaram, sobretudo, leis existentes. Muitas disposições foram extraídas dos direitos romano e canônico, quer diretamente, quer através das obras de comentadores. Pensa-se que o Livro das Leis e Posturas e as Ordenações de D. Duarte tenham sido trabalhos preparatórios de codificação afonsina. (ORDENAÇÕES, 2006). 
instituições oficiais. Pelo contrário, em texto de página na Internet, "Direitos e Desejos Humanos no Ciberespaço", há a seguinte afirmação:

\begin{abstract}
A única resposta é que ou os pobres ficavam completamente desamparados juridicamente ou este serviço acabava por recair sobre a classe dos advogados. Ora, vejamos, a estes profissionais restava acumular seus serviços particulares, dos quais dependia sua sobrevivência, com a "caridosa" prestação da assistência judiciária gratuita. Obviamente, tal sistema mereceu justas críticas por parte de muitos estadistas, aos quais não agradava ver a força de trabalho destes profissionais explorada, gratuitamente, pelo Estado. Tornou-se evidente o clamor de uma nova construção legislativa que regulasse de maneira mais justa o assunto.(ORIGEM, 2006).
\end{abstract}

Diante da falta de iniciativa por parte do Estado, é criado, em 1870, pelo Instituto dos Advogados Brasileiros, um Conselho com a finalidade de prestar assistência judiciária aos necessitados em causas civis e criminais.

Sobre tal Conselho, Humberto Peña Moraes (1984, p. 81), registra que Nabuco de Araújo, que na época era o presidente do Instituto da Ordem dos Advogados Brasileiros, foi o grande incentivador da assistência jurídica aos pobres e necessitados. Inconformado com a situação e diante da insuficiência de sua iniciativa e de seus companheiros. Nabuco de Araújo (apud MORAES, 1984, p. 85) disse:

\begin{abstract}
Se não se pode tudo, faz-se o que é possível. No estado actual da nossa legislação, e attendendo às despesas que uma demanda custa, pode-se dizer, sem medo de errar, que a igualdade perante a lei não é uma palavra vã. Que importa ter direito, se não é possível mantê-lo? Se um outro pode vir privar-nos delle? Que importa ter uma reclamação justa, se não podemos apresentál-la e seguil-la por falta de dinheiro? A lei é, pois, para quem tem dinheiro, para quem pode pagar as despesas das demandas (mantida a grafia da época).
\end{abstract}

Apesar de sua indignação e do esforço dos advogados, a atuação deles era insuficiente, tanto que apenas amenizavam o problema. A demanda, em relação ao número de pessoas que eram atendidas pelo Conselho de Advogados, era muito maior. A intervenção do Estado, através da criação de legislação específica que garantisse o direito a um defensor gratuito e também a isenção das custas processuais, já era uma necessidade urgente naquela época.

Humberto Peña Moraes (1984, p. 98) registra que somente após vinte e sete anos dos apelos de Nabuco de Araújo foi publicado, em 05 de maio de 1897, um decreto que 
instituiu a Assistência Judiciária na cidade do Rio de Janeiro, que na época era a capital do país. Tal órgão era constituído por uma Comissão Central e por várias Comissões Seccionais. De certo modo, não podemos considerar o Decreto como um grande avanço, pois seu alcance era local, não estendendo seus benefícios para além da cidade do Rio de Janeiro.

Mesmo com toda a carência da população, somente com a proclamação da República é que são editadas as primeiras normas sobre a assistência judiciária sustentada pelo Estado.

Em 1891 tivemos a nossa primeira Constituição Republicana, em tal Carta a assistência judiciária não foi mencionada, porém, em seu Art. 72, há menção à plena defesa:

$\S 16$ - Aos acusados se assegurará na lei a mais plena defesa, com todos os recursos e meios essenciais a ela, desde a nota de culpa, entregue em 24 horas ao preso e assinada pela autoridade competente com os nomes do acusador e das testemunhas (ORIGEM, 2006).

A Constituição Federal de 1934, no Título III, Capítulo II, Art. 113, n. 32 fazia menção ao direito de acesso gratuito à Justiça:

A união e os Estados concederão aos necessitados assistência judiciária, para esse efeito, órgãos especiais, e assegurando isenção de emolumentos, custas, taxas e selos.

Sobre tal dispositivo, em texto da página "Direitos e Desejos Humanos No Ciberespaço":

\footnotetext{
Como podemos observar esta Constituição trouxe à assistência judiciária importantes inovações, entre outras:

1. a competência concorrente da União e dos Estados para a concessão deste préstimo;

2. a criação de órgãos especiais e organizados com a finalidade desta prestação; e

3. a primeira alusão constitucional à justiça gratuita, através da "isenção de emolumentos, custas, taxas e selos (ORIGEM, 2006).
}

Humberto Peña Moraes (1984, p. 98) aponta que, desde a Constituição de 1934, os municípios foram excluídos da competência para legislar sobre assistência judiciária e sobre a criação dos órgãos mencionados. Situação esta que permanece até hoje.

Em 1935, o Estado de São Paulo foi precursor ao adotar o primeiro serviço estatal de Assistência Judiciária do Brasil. A iniciativa foi seguida pelos Estados do Rio Grande do Sul e Minas Gerais. 
Em contraste à iniciativa tomada pelo Estado em 1935, na atualidade, o Estado de São Paulo era, até o ano de 2006, quando entrou em vigor Lei Complementar 18/05, um dos Estados brasileiros onde a Defensoria Pública ainda não era instituída de acordo com a Constituição Federal e a Lei Complementar n. 80/94.

No Código de Processo Civil de 1939 havia um capítulo (Título VII, Capítulo II) com as regras básicas sobre Justiça Gratuita (BRASIL, 2006).

Na Constituição do Estado Novo, provavelmente por ser fruto de um período ditatorial, não havia previsão da Assistência Judiciária. Tal deficiência foi amenizada pela previsão da assistência judiciária no Código de Processo Civil de 1939.

Em 1946, com a nova Constituição, a assistência judiciária volta ao texto constitucional, em seu Art. 141, parágrafo 35:

O poder público, na forma que a Lei estabelecer, concederá assistência judiciária aos necessitados.

Da leitura do artigo observamos que foi assegurada a prestação da assistência jurídica aos necessitados, porém, não ficou estabelecido se esta prestação seria responsabilidade dos Estados ou da União e nem a forma de sua viabilização.

Tal omissão fez com que vários Estados criassem seus próprios órgãos de assistência. Os Estados que não criaram órgão específico para prestação do serviço começaram a credenciar advogados especiais para prestação da assistência.

Em 05 de fevereiro de 1950 foi editada a Lei 1060, que dispõe sobre a concessão da assistência judiciária aos necessitados. Há um erro na nomenclatura da Lei que explicaremos logo abaixo, pois, na verdade, ela trata das regras para concessão da Justiça Gratuita. A justiça gratuita e a assistência judiciária, apesar de estarem intimamente ligadas e convergirem para o mesmo objetivo, são conceitos diferentes que precisam ser divisados pelo leitor.

Os dispositivos do Código de Processo Civil que disciplinavam a Justiça Gratuita foram remetidos pelo Código de Processo Civil de 1973 para a referida Lei. Ela continua em vigor até hoje, pois foi recepcionada pela Constituição de 1988 e é, com certeza no nosso entender, um marco na luta pelo acesso à Justiça. 
Esta lei é o vetor pré-processual que assegura aos pobres o acesso à jurisdição pelo fato de tornar gratuito o processo, além de dispensar o pagamento de honorários de advogado e de peritos (MORAES, 1984, p. 93).

Apesar do seu relevante papel, como já dissemos acima, há um erro conceitual na Lei que precisa ser comentado: a confusão entre assistência judiciária e justiça gratuita.

Pontes de Miranda (1967, p. 460) esclarece a diferença entre os dois conceitos:

Assistência Judiciária e benefício da justiça gratuita não são a mesma coisa. 0 benefício da justiça gratuita é direito à dispensa provisória de despesas, exercível em relação jurídica processual, perante juiz que promete a prestação jurisdicional. É instituto de direito pré-processual. A Assistência Judiciária é organização estatal, ou paraestatal, que tem por fim, ao lado da dispensa provisória de despesas, a indicação de advogado. É instituto de direito administrativo.

A Constituição de 1988, no Art. 134, considera a Defensoria Pública, ao lado do Ministério Público e da Advocacia Pública, como função essencial à Justiça.

Apesar da unidade e indivisibilidade da instituição, ela se organiza em três ramos: Defensoria Pública da União, Defensoria Pública do Distrito Federal e dos Territórios e Defensoria Pública dos Estados.

Em que pese a precariedade da nossa Defensoria Pública o Brasil se destaca no panorama mundial como um dos poucos países que erige a Defensoria Pública, por mandamento constitucional, à condição de carreira de Estado, o que denota nosso elevado grau de maturidade democrática sob o ponto de vista formal (BRASIL, 2004).

O Estado do Rio de Janeiro possui a mais antiga Defensoria Pública do país, instalada em 1954, com 50 anos de atuação. Depois dela temos a Defensoria de Minas Gerais, que funciona há 23 anos. Os dois exemplos citados anteriormente fogem à regra, pois mais de 70 \% das Defensorias foram criadas após a Constituição de 1988 e têm em média 13 anos de existência (BRASIL, 2004).

Sobre a situação atual da Defensoria Pública o Ministério da Justiça assim se expressa:

Em todas as unidades da Federação, o número de defensores é menor do que o de magistrados. As Defensorias Públicas com as situações mais críticas no que se refere ano número de integrantes são as dos seguintes Estados: Alagoas, Espírito Santo, Mato Grosso, Piauí, Rondônia e Rio Grande do Sul, além do Distrito Federal. 
Em todos esses casos, o número de defensores não chega a representar $40 \%$ do número de juízes de primeiro grau.

Se considerarmos o número total de defensores em relação à população brasileira, concluímos que há no Brasil 1,86 defensores para cada 100.000 habitantes, enquanto dispomos de 7,7 juízes para cada grupo de 100.000 habitantes (BRASIL, 2004).

Apesar da importância da Instituição, conforme consta na afirmação acima, ela se encontra em uma situação difícil, necessitando de valorização e de investimento, apesar dos fundamentos nos quais se apóia.

\section{Conclusão}

Ao acompanhar a evolução histórica do que hoje chamamos de Defensoria Pública, o que concluímos é que apesar da percepção da sua indispensabilidade para alcançar a justiça, ela nunca foi tratada com urgência que o assunto merece.

Nos vários momentos históricos citados, a consciência de sua necessidade sempre existiu de alguma maneira, porém de forma precária porque só em alguns momentos ela se expressa, seja por iniciativas de particulares ou através de uma legislação incipiente e desvinculada da materialização das ações.

Atualmente, estão postas duas vertentes. Por um lado, está o direito de acesso à Justiça, garantido constitucionalmente, o que é um grande avanço, por outro, observa-se que a realidade continua a ser precária, pois em alguns Estados brasileiros, inclusive no Estado do Paraná, ainda não há a instituição da Defensoria Pública. Nos Estados em que ela já está devidamente instituída a situação pode ser considerada relativamente melhor, porém está longe de ser satisfatória. O número de defensores públicos nesses Estados é muito menor que o número necessário para atender toda a população carente, mas o que é mais grave, segundo dados do Estudo Diagnóstico/MJ, os Estados mais pobres são os que possuem o menor número de defensores públicos, situação esta que faz perpetuar um ciclo vicioso: os locais e pessoas mais pobres se tornam, a cada dia, ainda mais pobres e excluídos. ${ }^{5}$ Essa constatação, no nosso entender, é inadmissível, pois o Estado apesar de ter

5 Na expressiva maioria das unidades da Federação há comarcas não atendidas pelos serviços da Defensoria Pública. Em média são atendidas apenas 53\% das comarcas nos Estados em que há Defensoria Pública. Acrescente-se como mais um agravante, que as ausências não se distribuem ao acaso, ou uniformemente, ou em regiões onde as Defensorias seriam menos imprescindíveis ou mais facilmente substituíveis. Ao contrário, o maior percentual de comarcas não atendidas está exatamente nos Estados com os piores 
a obrigação/dever de agir em prol de tais cidadãos colabora com o processo de exclusão social de tais indivíduos ao negar direitos básicos como a Defensoria Pública.

Já decorridos dezoito anos da promulgação da Constituição de 1988, tempo suficiente para que a Defensoria Pública estivesse ao menos implantada em todos os Estados da Federação, sentimos a fragilidade da instituição, porque ela ainda não possui condições de cumprir sua missão: viabilizar o acesso universal à Justiça, uma vez que a necessária estruturação nas diversas unidades da Federação ainda não se concretizou.

Diante dessa realidade, de carência dos serviços do Estado através da Defensoria Pública, é preciso buscarmos foros de discussão que viabilizem a efetiva implantação da Defensoria Pública como instrumento de inclusão de uma multidão de desassistidos da Justiça brasileira. Sendo assim, esperamos que este trabalho desperte a atenção para o tema e que o assunto seja discutido sistematicamente até que tenhamos a Defensoria Pública devidamente instituída e atuando de forma satisfatória em todas as localidades do vasto território brasileiro.

\section{REFERÊNCIAS}

ALVES, José Carlos Moreira. Direito romano. 7.ed. Rio de Janeiro: Forense, 1992. v.1.

ARENHART, Sergio Cruz; MARINONI, Luiz Guilherme. Manual do processo de conhecimento. 3.ed. São Paulo: Revista dos Tribunais, 2004.

BOUZON, Emanuel. O código de Hamurabi: introdução. 10. ed. Petrópolis: Vozes, 2003.

BRASIL. Código civil: Código comercial: Código de processo civil: Constituição Federal. 2.ed. São Paulo: Saraiva, 2006.

BRASIL. Decreto lei no 1.608 de 18 de setembro de 1939. Disponível em: <ttp://www.planalto.gov.br/ccivil_03/Decreto-Lei/1937-1946/Del1608.htm> Acesso em: 18 dez. 2006.

BRASIL. Ministério da Justiça. Estudo diagnóstico: Defensoria Pública no Brasil. Brasília, DF: Ministério da Justiça, 2004.

indicadores de qualidade de vida, sendo significativa a entre a proporção de comarcas atendidas e os quartis de IDH. Verifica-se que quanto pior o Índice de Desenvolvimento Humano, mais baixa é a proporção de comarcas atendidas. (BRASIL, 2004, p. 73) 
CINTRA, Antônio Carlos de Araújo; DINAMARCO, Cândido Rangel; GRINOVER, Ada Pellegrini. Teoria geral do processo. 18.ed. São Paulo: Malheiros, 2003.

DEFENSORIA e cidadania. Disponível em:

<http://72.14.253.104/search?q=cache:JE7nb_ROSPOJ:www.defensoria.df.gov.br/artigos/his torico.html+\%22Em+sendo+o+agravante+t\%C3\%A3o+pobre+que+jure+n\%C3\%A3o+ter+ben $\mathrm{s}+\mathrm{m} \% \mathrm{C} 3 \%$ B3veis\%22\&hl=pt-BR\&ct=clnk\&cd=1\&gl=br>. Acesso em: $18 \mathrm{dez} .2006$.

HERKENHOFF, João Baptista. O direito processual e o resgate do humanismo. 2.ed. Rio de Janeiro: Thex, 1997.

LOPES, José Reinaldo de Lima. Uma introdução à história social e política do processo. 2003.

MORAES, Humberto Peña; SILVA, José Fontenelle Teixeira. Assistência judiciária: sua gênese, sua história e a função protetiva do estado. 2.ed. Rio de Janeiro: Líber Júris, 1984.

ORDENAÇÕES afonsinas. Disponível em:

<http://pt.wikipedia.org/wiki/Ordena\%C3\%A7\%C3\%B5es_Afonsinas>. Acesso em: 18 dez. 2006.

ORIGEM e história da assistência jurídica e da defensoria pública. Disponível em: <www.dhnet.org.br/3exec/defensoria/defensoria1.html>. Acesso em: 18 dez. 2006.

PONTES DE MIRANDA, Francisco Cavalcante. Comentários ao código de processo civil. 2.ed. Rio de Janeiro: Forense, 1967.

THEODORO JÚNIOR, Humberto. Curso de direito processual civil. 18. ed. Rio de Janeiro: Forense, 2004. v.1.

WOLKMER, Antonio Carlos (Org.). Fundamentos de história de direito. 2.ed. Belo Horizonte: Del Rey, 2003. 